Article

\title{
Poly(Poly(Ethylene Glycol) Methyl Ether Methacrylate) Grafted Chitosan for Dye Removal from Water
}

\author{
Bryan Tsai ${ }^{1}$, Omar Garcia-Valdez ${ }^{2}$, Pascale Champagne ${ }^{1}$ and Michael F. Cunningham ${ }^{2, *}$ \\ 1 Department of Civil Engineering, Queen's University, Kingston, ON K7L 3N6, Canada; \\ 0bt12@queensu.ca (B.T.); pascale.champagne@queensu.ca (P.C.) \\ 2 Department of Chemical Engineering, Queen's University, Kingston, ON K7L 3N6, Canada; \\ omargv86@gmail.com \\ * Correspondence: michael.cunningham@queensu.ca; Tel.: +1-613-533-2782
}

Academic Editor: Alexander Penlidis

Received: 1 February 2017; Accepted: 11 March 2017; Published: 14 March 2017

\begin{abstract}
As the demand for textile products and synthetic dyes increases with the growing global population, textile dye wastewater is becoming one of the most significant water pollution contributors. Azo dyes represent $70 \%$ of dyes used worldwide, and are hence a significant contributor to textile waste. In this work, the removal of a reactive azo dye (Reactive Orange 16) from water by adsorption with chitosan grafted poly(poly(ethylene glycol) methyl ether methacrylate) (CTS-GMA-g-PPEGMA) was investigated. The chitosan (CTS) was first functionalized with glycidyl methacrylate and then grafted with poly(poly(ethylene glycol) methyl ether methacrylate) using a nitroxide-mediated polymerization grafting to approach. Equilibrium adsorption experiments were carried out at different initial dye concentrations and were successfully fitted to the Langmuir and Freundlich adsorption isotherm models. Adsorption isotherms showed maximum adsorption capacities of CTS-g-GMA-PPEGMA and chitosan of $200 \mathrm{mg} / \mathrm{g}$ and $150 \mathrm{mg} / \mathrm{g}$, respectively, while the Langmuir equations estimated $232 \mathrm{mg} / \mathrm{g}$ and $194 \mathrm{mg} / \mathrm{g}$, respectively. The fundamental assumptions underlying the Langmuir model may not be applicable for azo dye adsorption, which could explain the difference. The Freundlich isotherm parameters, $n$ and $K$, were determined to be 2.18 and 17.7 for CTS- $g$-GMA-PPEGMA and 0.14 and 2.11 for chitosan, respectively. An " $n$ " value between one and ten generally indicates favorable adsorption. The adsorption capacities of a chitosan-PPEGMA 50/50 physical mixture and pure PPEGMA were also investigated, and both exhibited significantly lower adsorption capacities than pure chitosan. In this work, CTS- $g$-GMA-PPEGMA proved to be more effective than its parent chitosan, with a $33 \%$ increase in adsorption capacity.
\end{abstract}

Keywords: PEGMA; grafting; nitroxide-mediated polymerization; chitosan; wastewater; dye

\section{Introduction}

As the discharge of environmental pollutants in receiving waters continues to be a serious concern across the globe, it is important to develop effective approaches for their removal. Synthetic dyes found in wastewater effluents are of particular concern due to their high toxicity and low biodegradability in water [1]. They are used widely in the textile, pharmaceutical, cosmetics, and food industries because of their coloring capabilities. In the textile industry, an estimated 10,000 different dyes and pigments are used, and over $7 \times 10^{5}$ tons of synthetic dyes are annually produced worldwide; up to 200,000 tons of these dyes are discharged to receiving environments every year [2]. With the large quantities of dyes released and their known toxicity to aquatic environments, as well as to human health, the removal of textile dyes has received increasing research attention in recent years. Dyes have been reported to 
exhibit carcinogenicity, mutagenicity, and resistance to natural degradation [3]. Some of these dyes also have the potential to cause kidney failure and dysfunction of the brain and reproductive and central nervous systems.

Another important aspect of textile wastewater treatment is the de-colouration of dyes. Even in small amounts, dyes can be toxic to aquatic life and lead to changes in salinity and the visible coloration of receiving waters. Additionally, they can also reduce sunlight penetration, which hinders natural photosynthesis and disinfection processes [4]. Unfortunately, these dyes exhibit high stabilities to light, temperature, water, and detergents, allowing them to escape conventional physio-chemical and biological wastewater treatment processes [2,5]. Furthermore, textile industries consume a substantial amount of water in the dyeing process and have been classified as among the most polluting of all industrial sectors. Hence, as the demand for textile products and synthetic dyes increases with the growing global population, textile dye wastewater is becoming a more significant water pollution contributor.

Adsorption is one of the most commonly used approach for the treatment of wastewaters from the textile industry. The applications of most traditional wastewater treatment approaches are often limited by process cost, efficiency, and sludge handling requirements after treatment. Since adsorption processes are highly versatile in terms their applicability for a range of contaminants, their use has been growing in popularity. Additionally, their potential simplicity, economic feasibility, and high level of efficiency make them suitable solutions for the treatment of a number of wastewater contaminants. Adequate, cost-effective adsorbents that could provide sufficient adsorption capacity, adsorption rate, and mechanical strength are in increasing demand. Activated carbon has been reported to be very successful and efficient in adsorbing dyes, but its popularity has decreased due to its high market value and the operational costs associated with its use. Other adsorbents such as silicon polymers and kaolin have also been explored. Natural materials and polymers are often suggested alternatives to activated carbons because of their renewability and availability [3]. These natural materials can be used with or without pretreatment and can often be modified to selectively target particular pollutants under specific conditions. Polymeric adsorbents are demonstrating increasing advantages over activated carbon because of their simple processing and possibility for modifications. Moreover, polymeric adsorbents can be tailored to have reversible adsorption capabilities, meaning the adsorbent could be recovered through separation processes to separate the adsorbent from the dye from for future reuse.

One example of a natural polymer is chitosan (CTS) (Figure 1). Chitosan is a naturally abundant polysaccharide derived from chitin, which is found and harvested from crustacean shells. Chitin is one of the most abundant natural polymers in the world, second to cellulose, therefore making chitosan inexpensive and readily accessible. Among a wide range of applications, chitosan is a natural adsorbent and has been shown to adsorb substantial amounts of heavy metals and organic pollutants due to its high hydrophilicity and presence of amino and hydroxyl functional groups that serve as active sites for adsorption.

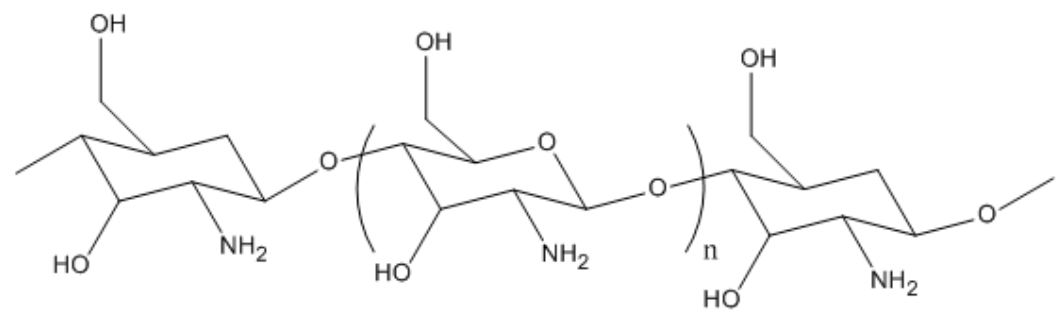

Figure 1. Chemical structure of chitosan.

The ability for chitosan to adsorb textile dyes has been well documented over the past decade, showing promising results and expanding its potential applications. Azo dyes are one of many classes of dyes and are characterized by having one or more azo groups $(-\mathrm{N}=\mathrm{N}-)$. Azo dyes represent $70 \%$ of 
dyes produced annually and consist of a wide range of classifications that describes their reactivity with the dyeing materials. Reactive azo dyes, specifically, are the most used due to their bright colors, excellent color fastness, and ease of application [5]. Reactive Orange 16 (RO16) (Figure 2) was selected as a representative reactive azo dye for this work as it is a commonly used textile dye.

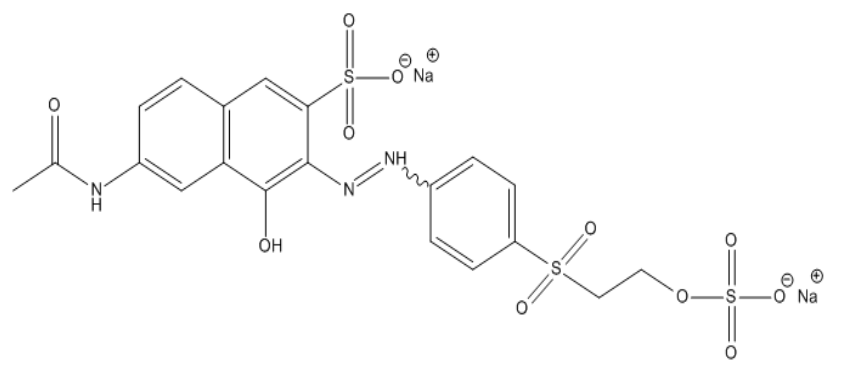

Figure 2. Chemical structure of Reactive Orange 16.

Polymer graft modification can introduce desired properties and broaden the field of potential applications for chitosan through the selection of different types of polymer side chains with different functionalities. By grafting and functionalizing additional side chains onto chitosan, the adsorption capacity of the grafted copolymer could potentially be increased. For reactive azo dyes, Singh et al. reported a poly(methyl methacrylate) (PMMA) grafted chitosan with an adsorption capacity for azo dyes of three times that of pure chitosan. In addition, a separate study demonstrated that triphenylphosphine (TPP) crosslinked chitosan improved the adsorption capacity of chitosan by $40 \%$ in the removal of reactive azo dyes [5]. These studies would suggest that with tailored polymeric side chains, the adsorption efficiency of chitosan can be improved extensively through functionalization. In this work, the adsorption capacity of glycidyl methacrylate (GMA) functionalized chitosan with grafted poly-(poly(ethylene glycol) methyl ether methacrylate) (PPEGMA) side chains (CTS- $g$-GMA-PPEGMA) was investigated and compared with pure chitosan for the removal of RO16 dye. PPEGMA has a similar structure to PMMA (Figure 3), and would therefore be expected to exhibit similar adsorption properties. PPEGMA also has repeating ester groups, while PMMA only has one, which would suggest that PPEGMA could yield higher adsorption capacities. More importantly, PPEGMA is water soluble, whereas PMMA is water insoluble. Since chitosan is soluble in water under acidic conditions, the synthesis of PPEGMA grafted chitosan could be performed in an aqueous system, in comparison to the synthesis of PMMA grafted chitosan which would require organic solvents, leading to a much greener and cost efficient process resulting from the reduction in organic waste solvents and fewer synthesis steps.

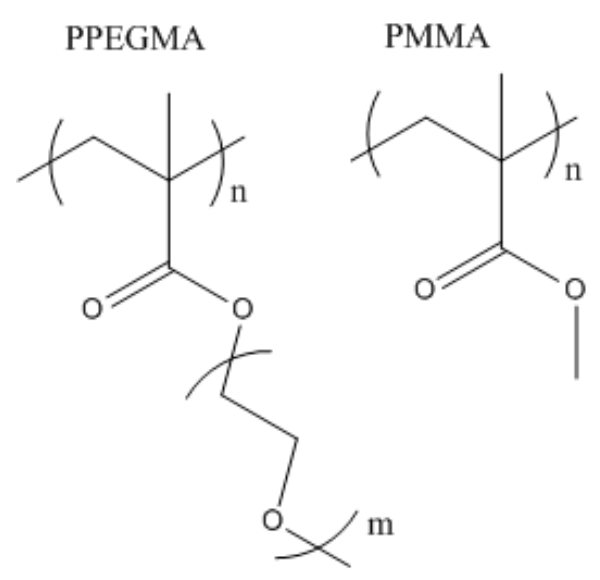

Figure 3. Chemical structure of poly-(poly(ethylene glycol) methyl ether methacrylate) (PPEGMA) and poly(methyl methacrylate) (PMMA). 
The modification of chitosan to yield application-specific properties can generally take place at the amino $\left(\mathrm{NH}_{2}\right)$ or primary hydroxyl $(\mathrm{OH})$ functionalities, although the amino functionality is mostly used. However, the natural adsorption capacity of chitosan is largely attributed to the $\mathrm{NH}_{2}$ group. As such, the hydroxyl group was targeted for the modification of chitosan in this work, hence preserving the $\mathrm{NH}_{2}$ functionality and its natural adsorption capacity. The modification of chitosan through polymer grafting was achieved via nitroxide-mediated polymerization and a grafting to approach [6]. The objective was to examine the adsorption capacity of CTS-g-GMA-PPEGMA for RO16 relative to pure chitosan in water for textile wastewater treatment applications. The present work describes the synthesis and application of PPEGMA-grafted chitosan for the removal of Reactive Orange 16. Figure 4 illustrates the steps we used in the synthesis of the CTS-g-GMA-PPEGMA. Batch adsorption experiments were carried out to develop adsorption isotherms for both chitosan and PPEGMA-grafted chitosan and experimental data were fitted to the Langmuir and Freundlich isotherms for the computation of respective equation parameter constants.

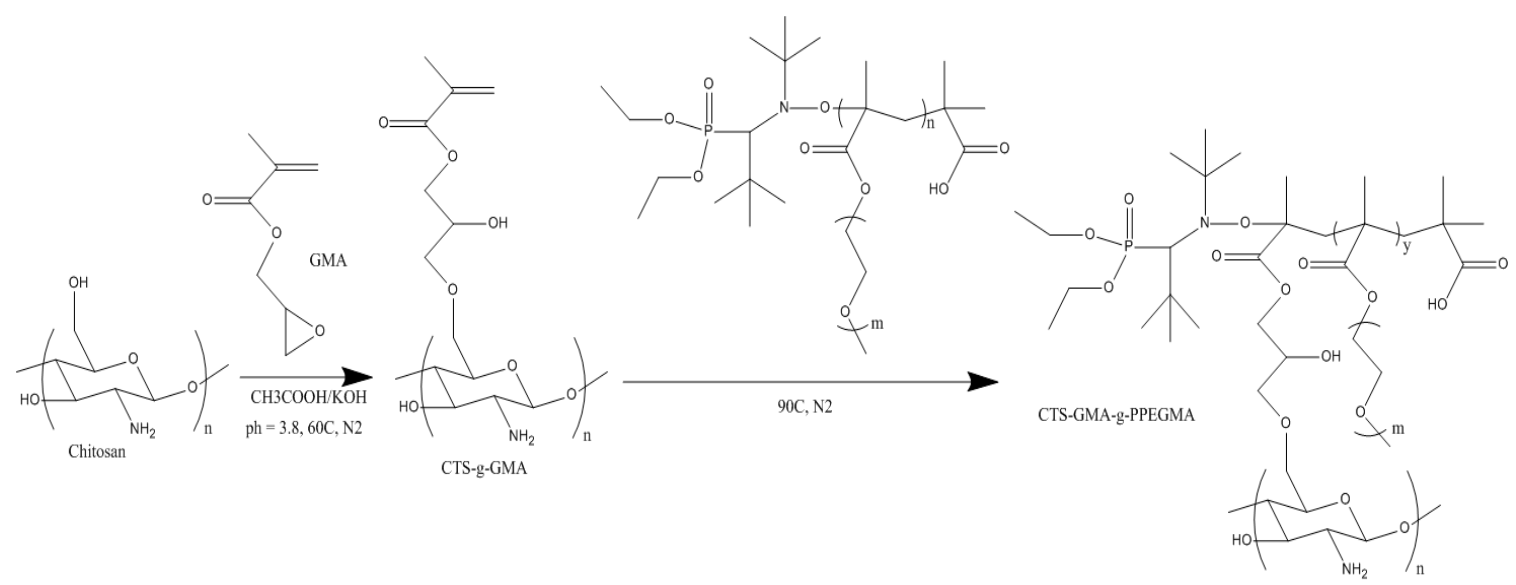

Figure 4. Synthesis of CTS-g-GMA-PPEGMA. CTS, $1 \mathrm{~g}$; $0.4 \mathrm{M}$ acetic acid solution, $100 \mathrm{~mL} ; 0.05 \mathrm{M}$ $\mathrm{KOH}$ solution, $5 \mathrm{~mL}$; hydroquinone solution $\left(9.09 \times 10^{-5} \mathrm{~mol}\right.$ in $10 \mathrm{~mL}$ of $\left.\mathrm{H}_{2} \mathrm{O}\right)$; glycidyl methacrylate (GMA) (0.024 mol, $3.53 \mathrm{~g}$, $3.30 \mathrm{~mL}$ ) was added to the system dropwise. The system was degassed for $30 \mathrm{~min}$ under nitrogen atmosphere prior to increasing the temperature to $65^{\circ} \mathrm{C}$ for $2 \mathrm{~h}$. $\mathrm{pH}$ of the mixture was 3.8 .

\section{Experimental}

\subsection{Materials}

Chitosan (CTS, Aldrich, Oakville, ON, Canada, low molecular weight, $85 \%$ degree of deacetylation), glycidyl methacrylate (GMA, Aldrich, 97\%), acetic acid (Fisher, Waltham, MA, USA, 99.7\%), and acetone (ACP, 99.5\%) were used as received. Poly(ethylene glycol) methyl ether methacrylate (PEGMA, Aldrich, Mn of $300 \mathrm{~g} / \mathrm{mol}$ ) and styrene (St, Aldrich, 99+\%) were passed through aluminum oxide columns (Aldrich, $\sim 150$ mesh, $58 \mathrm{~A}$ ) prior to polymerization. BlocBuilder (2-methyl-2-(N-tert-butyl- $N$-(1-diethoxyphosphoryl-2,2-dimethylpropyl)aminoxy)-propionic acid alkoxyamine) (BB, 99\%) and SG1 (4-(diethoxyphosphinyl)-2,2,5,5-tetramethyl-3-azahexane- $N$-oxyl) $(85 \%)$ were supplied by Arkema. Reactive Orange 16 was kindly supplied by the Ramsay research group in the Department of Chemical Engineering at Queen's University (Kingston, ON, Canada).

\subsection{Instrumentation}

${ }^{1} \mathrm{H}$ NMR spectroscopy was performed at room temperature on a FT-NMR Bruker Advance $400 \mathrm{MHz}$ spectrometer (Billerica, MA, USA) with a total of 256 scans, using $\mathrm{D}_{2} \mathrm{O}$ as the solvent at $5 \mathrm{mg} / \mathrm{mL}$. Thermogravimetric analysis (TGA) curves were recorded on TA Instruments Q500 TGA Analyzer (New Castle, DE, USA) by heating the sample from $75^{\circ} \mathrm{C}$ to $600^{\circ} \mathrm{C}$ at a rate $0 f 10{ }^{\circ} \mathrm{C}$ per 
minute. Gel Permeation Chromatography (GPC, Waters, Milford, MA, USA) analyses were performed with a Waters 2690 Separation Module and Waters 410 Differential Refractometer with THF as the eluent. Adsorption experiments were conducted using a WSR Shaker Model 3500 (VWR, Radnor, PA, USA) and Lambda XLS Spectrometer (Perkin Elmer, Waltham, MA, USA).

\subsection{Synthesis of CTS-g-GMA}

The functionalization of chitosan with GMA followed a previously published synthesis approach by García-Valdez et al. [6]. Chitosan ( $1 \mathrm{~g})$ was first dissolved in $100 \mathrm{~mL}$ of acetic acid $(0.4 \mathrm{M})$ in a three neck round bottom flask with $5 \mathrm{~mL}$ of $0.05 \mathrm{M}$ potassium hydroxide $(\mathrm{KOH})$ and $10 \mathrm{~mL}$ of $9.08 \mathrm{M}$ hydroquinone. The flask was then purged with nitrogen for $30 \mathrm{~min}$ and heated to $60^{\circ} \mathrm{C}$ in an oil bath. GMA was added drop wise at $60^{\circ} \mathrm{C}$ and magnetically stirred for $2 \mathrm{~h}$. CTS-g-GMA was precipitated in acetonitrile, washed with THF and dried for ${ }^{1} \mathrm{H}$ NMR and TGA analysis.

\subsection{Synthesis of Poly(PEGMA) via Nitroxide-Mediated Polymerization}

PEGMA monomer ( $50 \mathrm{~g}, 53 \mathrm{~mL})$, styrene $(1.92 \mathrm{~g}, 2.14 \mathrm{~mL})$, BlocBuilder $(0.70 \mathrm{~g})$, and $0.06 \mathrm{~mL}$ of SG1 were mixed in a three neck round bottom flask with magnetic stirring and oxygen purging for $30 \mathrm{~min}$. (A small amount of styrene comonomer provides better control over the PEGMA polymerization). The flask was then heated to $90{ }^{\circ} \mathrm{C}$ for one hour. Unreacted monomer was removed through precipitation in diethyl ether. The polymer was dried under vacuum and analyzed by ${ }^{1} \mathrm{H}$ NMR and TGA.

\subsection{Synthesis of CTS-GMA-g-PPEGMA via Grafting to Approach}

The modification of CTS- $g$-GMA was carried out following a previously reported approach developed in our research group [5]. Briefly, CTS- $g$-GMA $(1 \mathrm{~g})$ was dissolved in $100 \mathrm{~mL}$ of $0.1 \mathrm{M}$ acetic acid in a three neck round bottom flask. $\mathrm{KOH}$ was added to the CTS-g-GMA solution to increase the $\mathrm{pH}$ to 5 and mechanically stirred under nitrogen for $30 \mathrm{~min}$ before increasing the temperature to $90^{\circ} \mathrm{C}$. PPEGMA ( $0.5 \mathrm{~g})$ was dissolved in $60 \mathrm{~mL}$ of de-ionized (DI) water and was purged of oxygen in an inert nitrogen atmosphere. $20 \mathrm{~mL}$ PPEGMA was added every $30 \mathrm{~min}$ once the CTS-g-GMA solution reached $90{ }^{\circ} \mathrm{C}$ and the reaction was left to react for an additional $1.5 \mathrm{~h}$. CTS-g-GMA-PPEGMA was washed in THF and extracted using a rotary evaporator.

\subsection{Dye Adsorption Experiments}

A 100 ppm dye stock solution (100 mg in $1 \mathrm{~L}$ of DI water) was diluted to lower concentrations for the construction of a calibration curve. Concentrations ranged from $0.5 \mathrm{ppm}$ to $80 \mathrm{ppm}$ with a $R^{2}$ of 0.99 . The $\lambda_{\max }$ of RO16 dye was measured to be $494 \mathrm{~nm}$. Adsorption experiments were carried out using CTS-g-GMA-PPEGMA, chitosan, chitosan-PPEGMA (50/50) physical mixture, and PPEGMA as adsorbents on an orbital shaker table set at $240 \mathrm{rpm}$. The experiments were conducted at room temperature for a predetermined equilibrium time of $36 \mathrm{~h}$ and neutral $\mathrm{pH}$. Each adsorbent was thoroughly mixed with $20 \mathrm{~mL}$ dye solution, and once the samples were shaken for the desired experimental time, the suspensions were filtered through Whatman $0.90 \mathrm{~mm}$ filter paper. The aqueous dye samples were diluted, if necessary, and analyzed for dye concentration. Initial dye concentrations ranged from 20 to $1200 \mathrm{ppm}$ with $50 \mathrm{mg}$ of adsorbent and each adsorption batch experiment was conducted in duplicate. The adsorption capacity of each adsorbent from the equilibrium solution was calculated using Equation (1).

$$
Q_{e}=\left(C_{o}-C_{e}\right) \times \frac{V}{W}
$$

where $Q_{e}$ is the adsorption capacity, describing the mass of dye adsorbed $(\mathrm{mg})$ for each gram of adsorbent $(\mathrm{mg} / \mathrm{g}), C_{o}$ is the initial concentration of dye in $\mathrm{mg} / \mathrm{L}, C_{e}$ is the equilibrium concentration of dye in solution $(\mathrm{mg} / \mathrm{L}), V(\mathrm{~L})$ is the volume of dye solution and $W(\mathrm{~g})$ is the weight of the adsorbent used. 


\section{Results and Discussion}

\subsection{CTS-g-GMA}

The ${ }^{1} \mathrm{H}$ NMR of CTS- $g$-GMA (Figure 5) shows several peaks that would distinguish it from pure CTS. The ${ }^{1} \mathrm{H}$ NMR for chitosan showed a singlet and a doublet between 3-4 ppm, as expected. The proton neighboring the amino group had an expected chemical shift at 2-3 ppm, while the protons around the primary and secondary alcohol exhibited chemical shifts at 3.5-4 ppm. When compared to the results of CTS-g-GMA, additional signals were observed at 4.3 ppm and between 5.5-6 ppm. The doublet observed at $4.3 \mathrm{ppm}$ was identified represent the protons neighboring the ether (HC-OR) and the alcohol (HC-OH) groups on GMA, which had an expected chemical shift at 3.3-4.3 ppm. Further confirmations of the presence of GMA were two signals observed between 5.5-6 ppm. The vinylic double bond $(\mathrm{C}=\mathrm{C}-\mathrm{H})$ on GMA was believed to be responsible for these two signals, with expected chemical shifts in the range of 5.5-7.5 ppm.

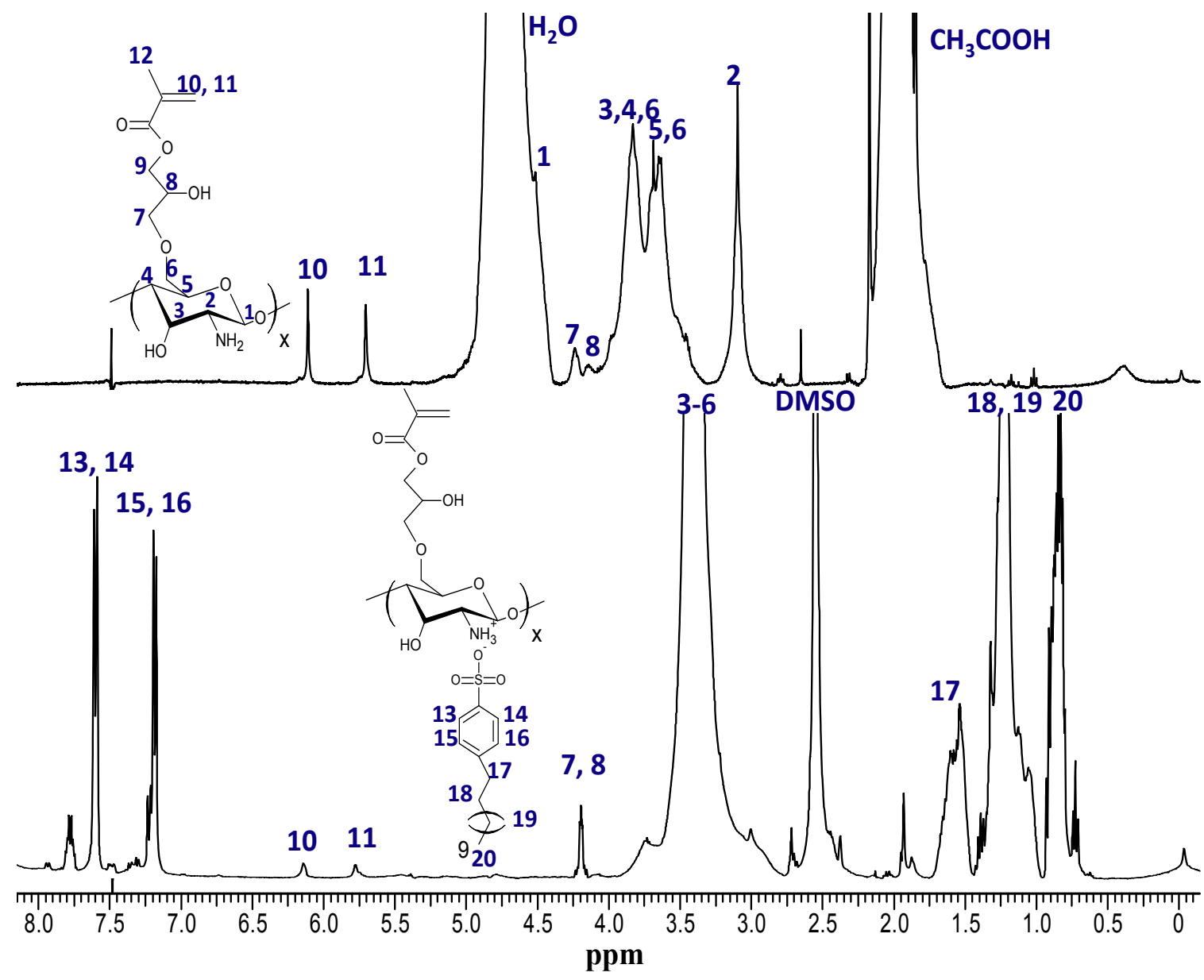

Figure 5. ${ }^{1} \mathrm{H}$ NMR of CTS- $g$-GMA (Top) and CTS (Bottom).

\subsection{PPEGMA}

The TGA curve of PPEGMA (Figure 6) showed a thermal decomposition of the material starting at around $340{ }^{\circ} \mathrm{C}$ and ending at $400{ }^{\circ} \mathrm{C}$. GPC results (Figure 7) of PPEGMA showed a relatively narrow peak, which indicates that the PPEGMA polymerization was well controlled. The average molecular weight $(\mathrm{Mn})$ was $11,500 \mathrm{~g} / \mathrm{mol}$ with a dispersity $(\bigoplus)$ of 1.18 . 


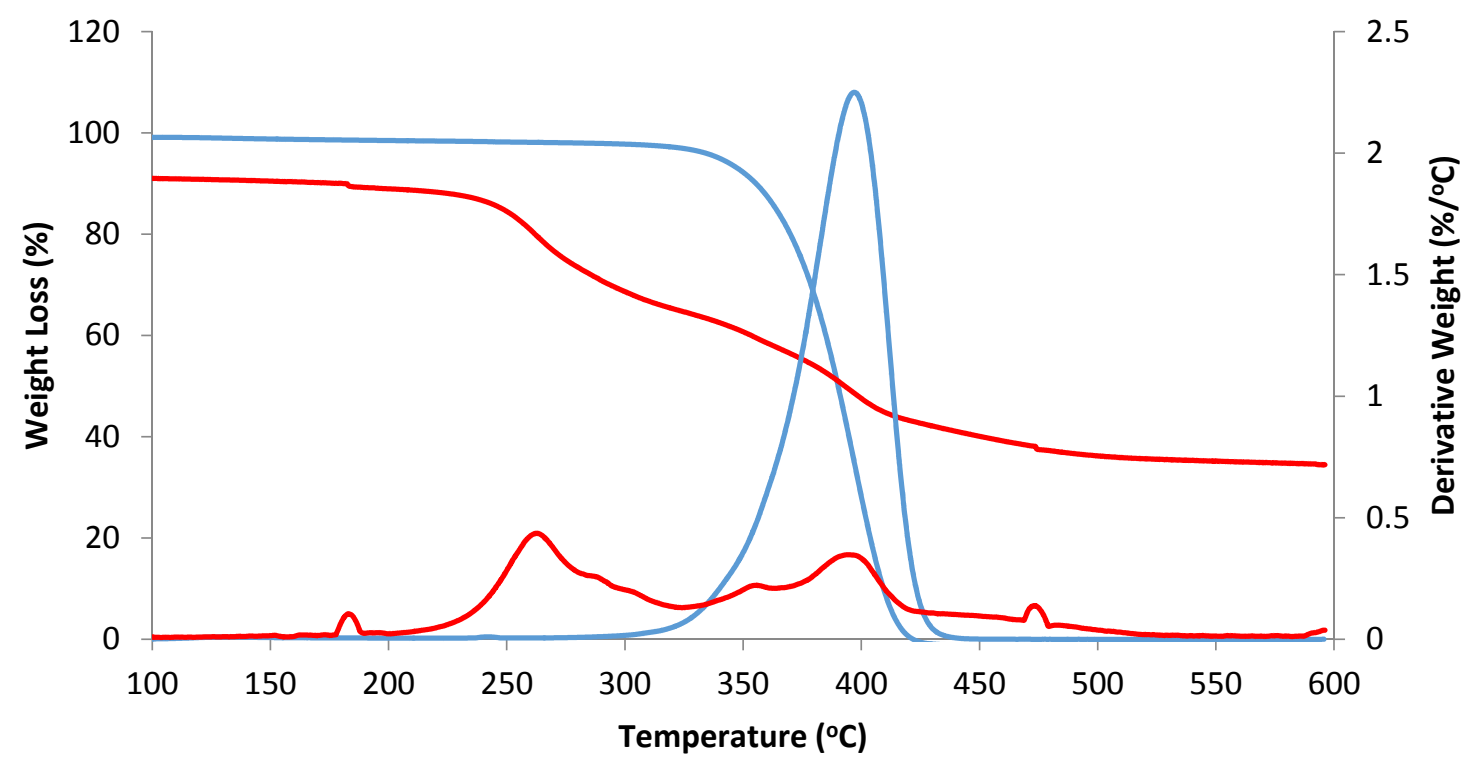

Figure 6. Thermogravimetric analysis (TGA) of PPEGMA (blue line) and CTS-g-GMA-PPEGMA (red line).

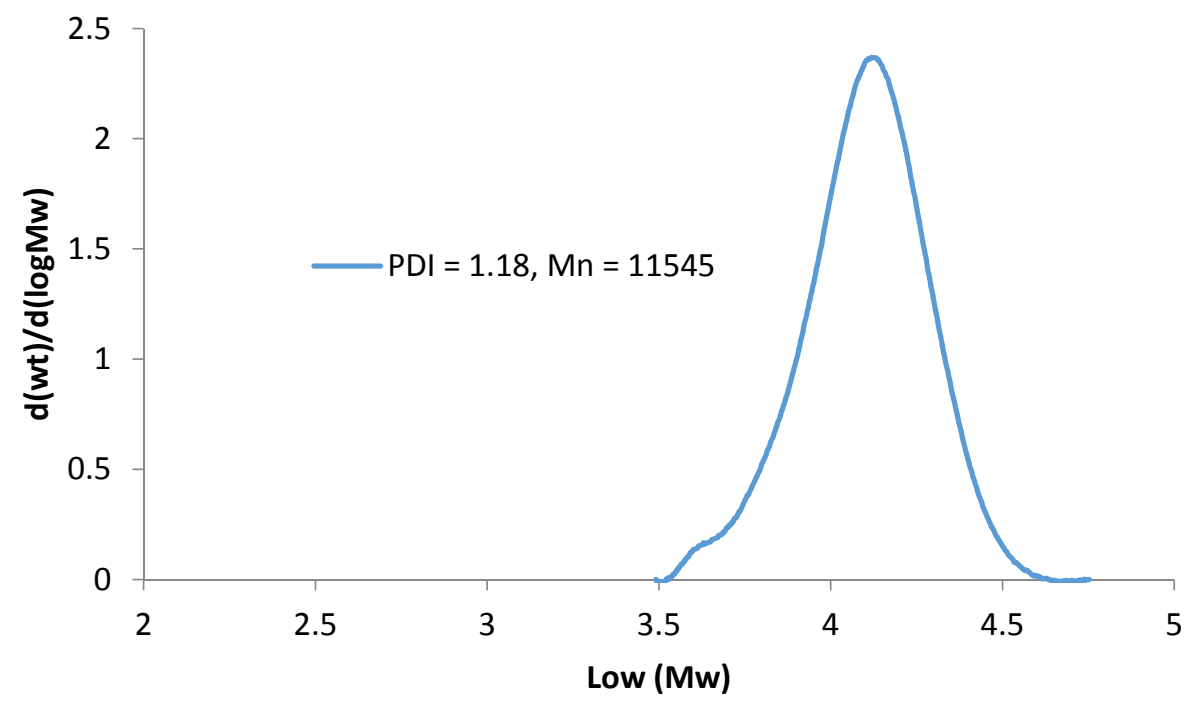

Figure 7. Gel Permeation Chromatography (GPC) analysis of the polymerization of PPEGMA via NMP.

\subsection{CTS-g-GMA-PPEGMA}

TGA results shown in Figure 6 characterized the decomposition of the grafted polymer starting at approximately $200{ }^{\circ} \mathrm{C}$ and ending at $500{ }^{\circ} \mathrm{C}$. The first weight loss of the material from $200{ }^{\circ} \mathrm{C}$ to $340{ }^{\circ} \mathrm{C}$ was attributed to the decomposition of the chitosan backbone, while PPEGMA decomposed between 340 and $500{ }^{\circ} \mathrm{C}$. The synthesized CTS-g-GMA-PPEGMA was estimated to be approximately $55 \%$ CTS and $45 \%$ PPEGMA. ${ }^{1} \mathrm{H}$ NMR (Figure 8 ) showed multiple defining peaks for CTS- $g$-GMA-PPEGMA. The medium intensity peak at $3.25 \mathrm{ppm}$ represented the methyl groups at the end of PEGMA chains, while the high intensity peaks around $3.5 \mathrm{ppm}$ were the repeating $\left(\mathrm{O}-\mathrm{CH}_{2} \mathrm{CH}_{2}\right)$ chains. When compared with the ${ }^{1} \mathrm{H}$ NMR result for CTS-g-GMA, traces of CTS-g-GMA could still be seen. More importantly, signals for the double bonds on the GMA chains could still be observed, with significantly reduced intensity, thus indicating that most GMA double bonds were reacted. 


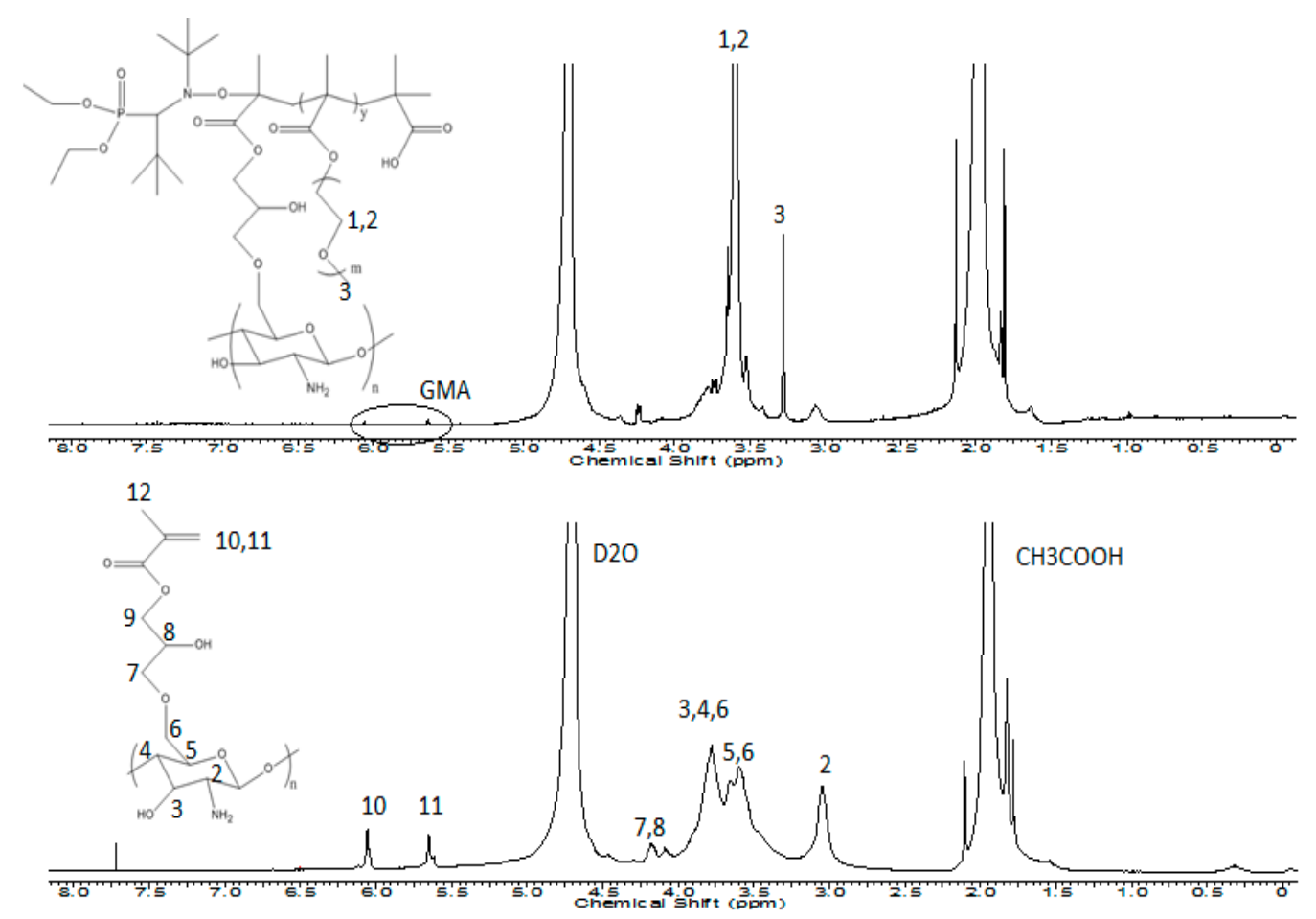

Figure 8. ${ }^{1} \mathrm{H}$ NMR of CTS-g-GMA-PPEGMA (Top) and CTS-g-GMA (Bottom).

\subsection{Adsorption Isotherms}

Although a number of different isotherm models exist that can be used to characterize an adsorption system, the Langmuir and Freundlich models are the most commonly used for the characterization of adsorbents in water and wastewater treatment applications [7]. Hence, these models were employed to estimate the adsorption capacities of chitosan, PPEGMA, CST-g-GMA-PPEGMA, and mixture of $50 \%$ chitosan and 50\% PPEGMA. It is important to establish reliable correlations for the equilibrium curves of the adsorption system. The adsorption isotherms shown in Figure 9 illustrate the adsorption capacity of each material. The equilibrium curves were linearized using the Langmuir and Freundlich models to calculate the model adsorption parameters (Table 1).

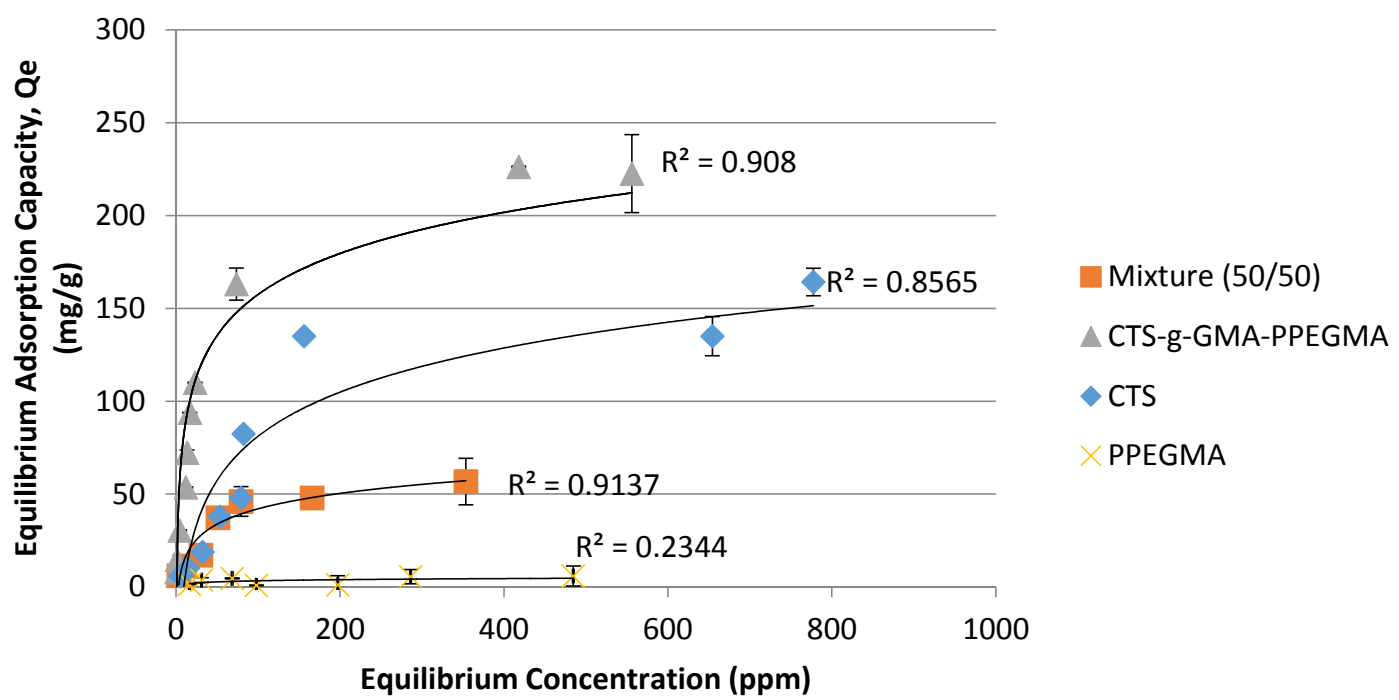

Figure 9. Adsorption isotherm. 
Table 1. Langmuir and Freundlich Isotherm constants.

\begin{tabular}{ccccccc}
\hline \multirow{2}{*}{ Sample } & \multicolumn{3}{c}{ Langmuir } & \multicolumn{3}{c}{ Freundlich } \\
\cline { 2 - 7 } & $\boldsymbol{Q}_{\max }(\mathbf{m g} / \mathbf{g})$ & $\boldsymbol{K}(\mathbf{L} / \mathbf{m g})$ & $\boldsymbol{R}^{\mathbf{2}}$ & $\boldsymbol{n}$ & $\boldsymbol{K}(\mathbf{m g} / \mathbf{g})$ & $\boldsymbol{R}^{\mathbf{2}}$ \\
\hline CTS & 196 & 0.005 & 0.926 & 0.143 & 2.12 & 0.9011 \\
Mixture (50/50) & 64 & 0.021 & 0.9791 & 1.93 & 3.53 & 0.9297 \\
CTS-g-GMA-PPEGMA & 232 & 0.039 & 0.9977 & 2.18 & 17.8 & 0.9404 \\
PPEGMA & 7 & 0.003 & 0.1371 & 2.82 & 0.763 & 0.1231 \\
\hline
\end{tabular}

\subsection{Langmuir Model}

The Langmuir model describes the formation of a monolayer of adsorbate (dye) on the outer surface of the adsorbent at adsorption equilibrium. The Langmuir model assumes that the surface of the adsorbent is uniform and that the adsorbed molecules do not interact. The model is described by

$$
\frac{Q_{e}}{Q_{m}}=\frac{C_{e} K}{1+K C_{e}}
$$

Equation (2) can be rearranged into its linear form for the determination of the Langmuir adsorption parameters.

$$
\frac{C_{e}}{Q_{e}}=C_{e} \frac{1}{Q_{m}}+\frac{1}{K Q_{m}}
$$

$C_{e}=$ equilibrium concentration $(\mathrm{mg} / \mathrm{L})$

$Q_{e}=$ equilibrium adsorption $(\mathrm{mg} / \mathrm{g})$

$Q_{m}=$ maximum monolayer adsorption capacity $(\mathrm{mg} / \mathrm{g})$

$K=$ Langmuir isotherm constant

According to the Langmuir plot (Figure 10), the maximum adsorption capacities of RO16 were 232, 196, and $64 \mathrm{mg} / \mathrm{g}$ for CTS-g-GMA-PPEGMA, chitosan, and the 50/50 chitosan-PPEGMA physical mixture, respectively. Pure PPEGMA exhibited negligible adsorption capacities the mixture yielded relatively low adsorption capacities due to its lower chitosan content. Since negligible adsorption was noted with PPEGMA, lower adsorption capacities were expected for the physical mixture. More interestingly, the model showed higher sorption capacity with the grafted chitosan than with chitosan alone. This confirmed that the chitosan modification improved the adsorption efficiency. The high $R^{2}$ values indicated that the data were a good fit for the Langmuir model.

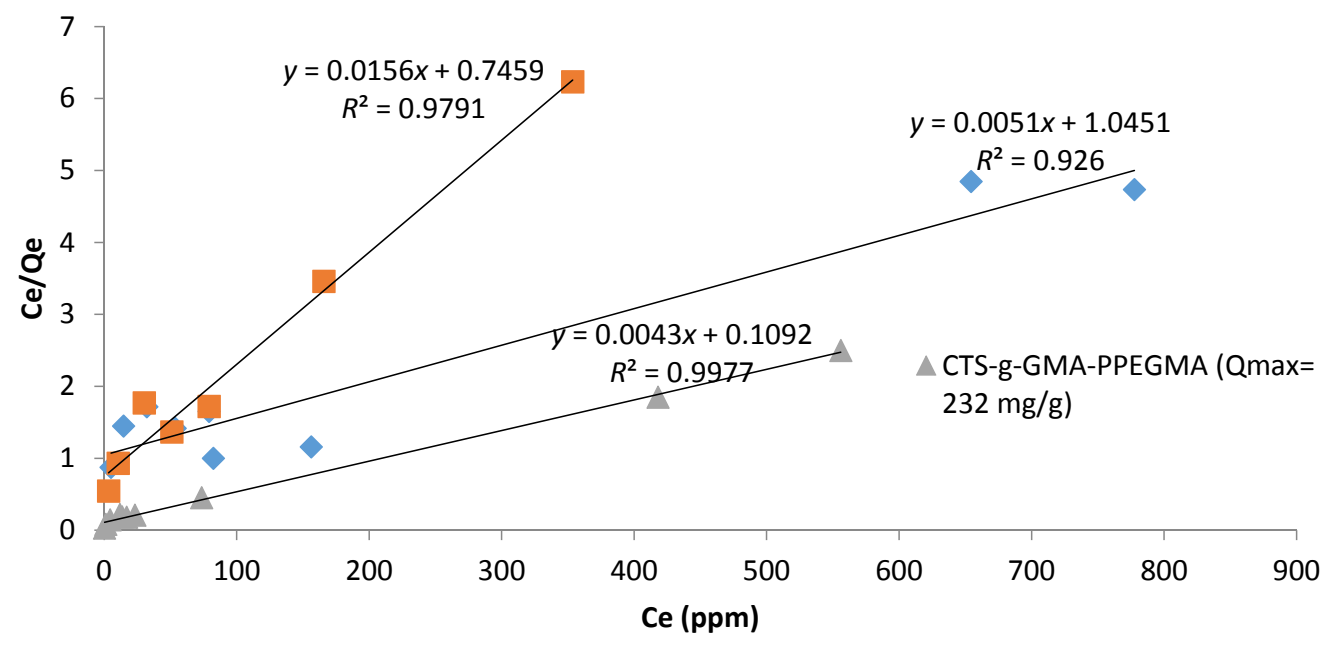

Figure 10. Linearized Langmuir isotherm. 
From the adsorption isotherm, the maximum adsorption capacities were noted to be $200 \mathrm{mg} / \mathrm{g}$ for CTS-g-GMA-PPEGMA and $150 \mathrm{mg} / \mathrm{g}$ for chitosan, where were different from the Langmuir model predictions. This could suggest that the adsorption of RO16 does not form a monolayer at maximum adsorption, as assumed by Langmuir model, but that adsorption layers are likely heterogeneous. CTS-g-GMA-PPEGMA increased the adsorption capacity by $33 \%$ according to the adsorption isotherm data, indicating that CTS- $g$-GMA-PPEGMA could be an effective adsorbent.

\subsection{Freundlich Model}

The Freundlich model is based on sorption onto a heterogeneous surface, as described by Equation (3), where $K$ and $n$ are Freundlich adsorption constants, indicators of adsorption capacity and intensity. $Q_{e}(\mathrm{mg} / \mathrm{g})$ and $C_{e}(\mathrm{mg} / \mathrm{L})$ are the equilibrium sorption capacity and equilibrium concentration values. The Freundlich equation can be linearized in the form of Equation (4). Calculated parameters are summarized in Table 1. The linearized Freundlich plot is shown in Figure 11.

$$
\begin{gathered}
Q_{e}=K C_{e}^{\frac{1}{n}} \\
\ln Q_{e}=\frac{1}{n} \ln C_{e}+\ln K
\end{gathered}
$$

The computed $n$ and $K$ values were 2.18 and 17 for CTS- $g$-GMA-PPEGMA and 0.14 and 2.12 chitosan, respectively. Experimental data for pure PPEGMA did not fit either of the isotherm models, which would be consistent with observation that pure PPEGMA exhibited negligible adsorption capacity for RO16. The parameter $\mathrm{n}$ is related to the heterogeneity parameter of the sorbent-sorbate system [8], where larger $\mathrm{n}$ values typically represent greater expected heterogeneities. For well-fitted data in the Freundlich model, an $\mathrm{n}$ value between one and ten would indicate a favorable adsorption process, thus suggesting that, in our study, the grafted copolymer performed more favorably than chitosan in its adsorption of the RO16.

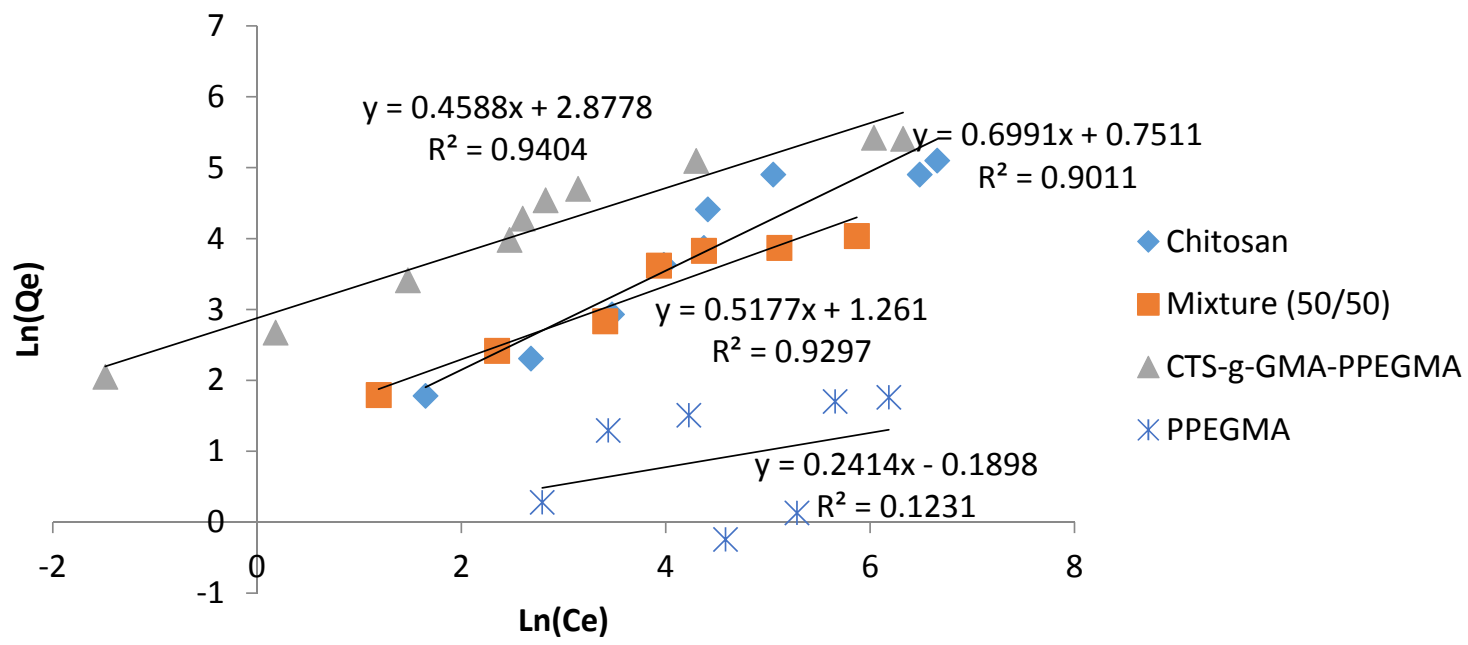

Figure 11. Linearized Freundlich isotherm.

\subsection{Effect of Initial Dye Concentration}

Figure 12 displays the equilibrium sorption efficiencies of RO16 for initial dye concentrations ranging from 20 to $1200 \mathrm{ppm}$ (room temperature and neutral $\mathrm{pH}$ ). The general trend indicated that the highest sorption efficiencies were noted at lower initial concentrations. For CTS-g-GMA-PPEGMA, the amount adsorbed started to decrease at $300 \mathrm{ppm}$, eventually reaching 50\% sorption at $1200 \mathrm{ppm}$. Increasing the initial concentration decreases the total quantity of dye adsorbed because dye ions at lower concentrations would have more access and interactions with the sorption sites on the adsorbent than at higher concentrations. At high concentrations, the adsorption sites would become saturated 
more readily, thereby limiting access to the sorption sites. In addition, increasing initial concentrations also increased the adsorption capacity of the adsorbent, increasing the driving force facilitated through the concentration gradient.

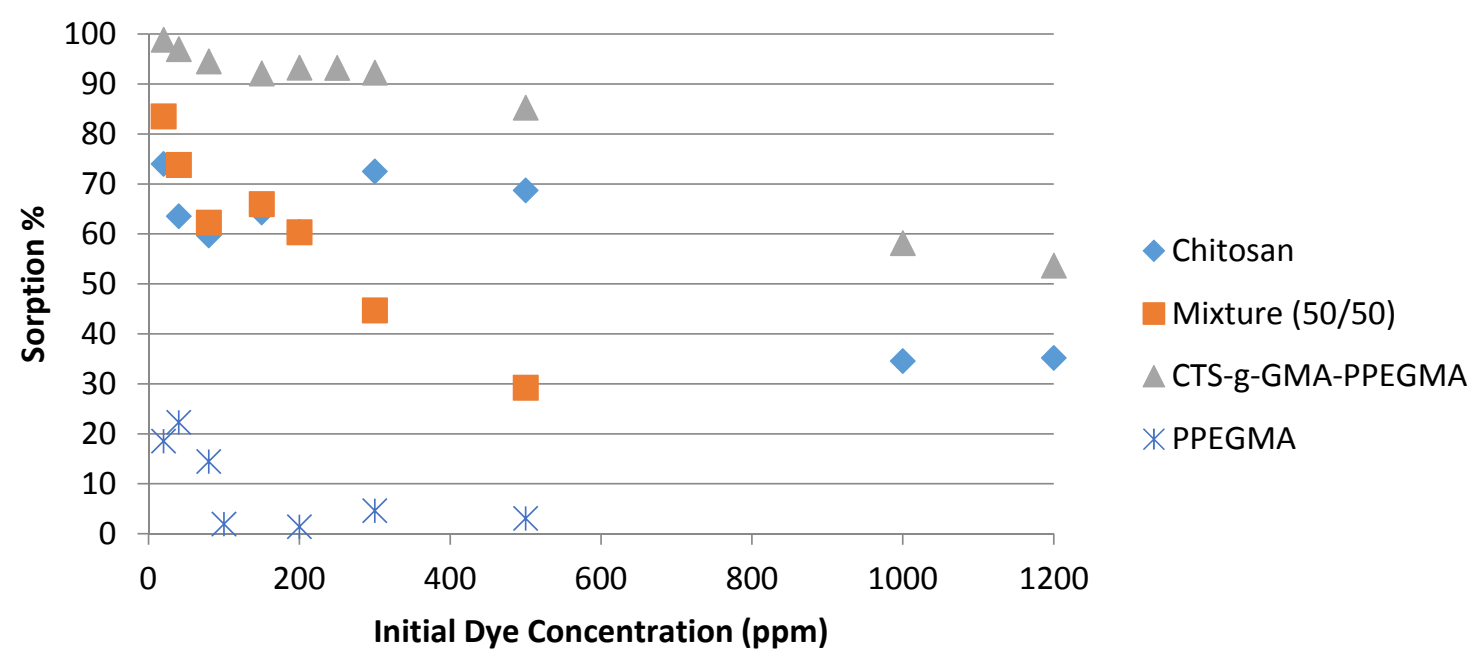

Figure 12. Adsorption \% at different initial dye concentrations.

\section{Conclusions}

Chitosan was functionalized with the vinyl monomer glycidyl methacrylate and then PPEGMA was grafted to the chitosan backbone. The PPEGMA was prepared by nitroxide-mediated polymerization conducted in an aqueous system, giving a narrowly distributed polymer with controlled molecular weight. The CTS-g-GMA-PPEGMA exhibited good adsorption capacity for the removal of the organic dye RO16 from water. CTS-g-GMA-PPEGMA proved to be a better adsorbent than chitosan, improving the adsorption efficiency of chitosan by $33 \%$. The estimated Freundlich isotherm parameters derived from the experiments suggested a more favorable adsorption process for the grafted material than for chitosan alone, which was consistent with the experimental observations. The 50/50 chitosan-PPEGMA physical mixture showed a $~ 50 \%$ decrease in adsorption capacity compared to chitosan alone, while negligible adsorption was observed with PPEGMA alone. This work only offers a preliminary outlook on the adsorption capacity of CTS-g-GMA-PPEGMA for textile dyes. The results of this study have potential to be useful in real textile wastewater treatment processes. Further research and studies would be required to simulate real textile wastewater properties such as $\mathrm{pH}$, temperature, suspended solids, and recyclability of the adsorbent material. From an adsorbent formulation perspective, exploration of the effects of PPEGMA loading on the CTS and the PPEGMA molecular weight on adsorption behaviour would be beneficial.

Acknowledgments: The Natural Sciences and Engineering Research Council of Canada (NSERC), the Ontario Research Chairs Program (MFC), and the Canada Research Chairs Program (PC) provided financial support.

Author Contributions: O.G.-V., P.C. and M.F.C. conceived and designed the experiments; B.T. and O.G.-V. performed the experiments and analyzed the data; B.T. and O.G.-V. wrote the paper.

Conflicts of Interest: The authors declare no conflict of interest.

\section{References}

1. Umpuch, C.; Sakew, S. Adsorption characteristics of reactive black 5 onto chitosan-intercalated motmorillonite. Desalin. Water Treat. 2015, 53, 2962-2969. [CrossRef]

2. Chequer, F.M.; Oliveira, G.A.; Ferraz, E.R.A.; Cardoso, J.C.; Zanoni, M.V.B.; Oliveira, D.P. Textile Dyes: Dyeing Process and Environmental Impact. In Eco-Friendly Textile Dyeing and Finishing; Günay, M., Ed.; Intech: Sao Paulo, Brazil, 2013; Chapter 6. 
3. Panic, V.V.; Seslija, S.I.; Nesic, A.R.; Velickovic, S.J. Adsorption of azo dyes on polymer materials. Hem. Ind. 2013, 67, 881-900. [CrossRef]

4. Liu, L.; Hall, G.; Champagne, P. Effects of environmental factors on the disinfection performance of a wastewater stabilization pond operated in temperate climate. Water 2016, 8, 5-15. [CrossRef]

5. Singh, V.; Sharma, A.; Tripathi, D.; Sanghi, R. Poly(methylmehtacrylate) grafted chitosan: An efficient adsorbent for anionic azo dyes. J. Hazard. Mater. 2009, 161, 955-966. [CrossRef] [PubMed]

6. García-Valdez, O.; George, S.; Champagne-Hartley, R.; Saldívar-Guerra, E.; Champagne, P.; Cunningham, M.F. Modification of Chitosan with polystyrene and poly( $n$-butyl acrylate) via nitroxide-mediated polymerization and grafting from approach in homogeneous media. Polym. Chem. 2015, 6, 2827-2836. [CrossRef]

7. Ozacar, M.; Sengil, I.A. Adsorption of acid dyes from aqueous solutiosn by calcined alunite and granular actuvated carbon. Adsorption 2002, 8, 301-308. [CrossRef]

8. Dada, A.; Olalekan, A.; Olatunya, A. Langmuir, freundlich, temkin and dubinin-radushjevich isotherms studies of equilibrium sorption of $\mathrm{Zn}^{2+}$ unto phosphoric acid modified rice husk. J. Appl. Chem. 2012, 3, $38-45$.

(C) 2017 by the authors. Licensee MDPI, Basel, Switzerland. This article is an open access article distributed under the terms and conditions of the Creative Commons Attribution (CC BY) license (http://creativecommons.org/licenses/by/4.0/). 